NASA/CR—2004-213364

\title{
Application of the GRC Stirling Convertor System Dynamic Model
}

Timothy F. Regan and Edward J. Lewandowski Sest, Inc., Middleburg Heights, Ohio 
Since its founding, NASA has been dedicated to the advancement of aeronautics and space science. The NASA Scientific and Technical Information (STI) Program Office plays a key part in helping NASA maintain this important role.

The NASA STI Program Office is operated by Langley Research Center, the Lead Center for NASA's scientific and technical information. The NASA STI Program Office provides access to the NASA STI Database, the largest collection of aeronautical and space science STI in the world. The Program Office is also NASA's institutional mechanism for disseminating the results of its research and development activities. These results are published by NASA in the NASA STI Report Series, which includes the following report types:

- TECHNICAL PUBLICATION. Reports of completed research or a major significant phase of research that present the results of NASA programs and include extensive data or theoretical analysis. Includes compilations of significant scientific and technical data and information deemed to be of continuing reference value. NASA's counterpart of peerreviewed formal professional papers but has less stringent limitations on manuscript length and extent of graphic presentations.

- TECHNICAL MEMORANDUM. Scientific and technical findings that are preliminary or of specialized interest, e.g., quick release reports, working papers, and bibliographies that contain minimal annotation. Does not contain extensive analysis.

- CONTRACTOR REPORT. Scientific and technical findings by NASA-sponsored contractors and grantees.
- CONFERENCE PUBLICATION. Collected papers from scientific and technical conferences, symposia, seminars, or other meetings sponsored or cosponsored by NASA.

- SPECIAL PUBLICATION. Scientific, technical, or historical information from NASA programs, projects, and missions, often concerned with subjects having substantial public interest.

- TECHNICAL TRANSLATION. Englishlanguage translations of foreign scientific and technical material pertinent to NASA's mission.

Specialized services that complement the STI Program Office's diverse offerings include creating custom thesauri, building customized databases, organizing and publishing research results ... even providing videos.

For more information about the NASA STI Program Office, see the following:

- Access the NASA STI Program Home Page at http://www.sti.nasa.gov

- E-mail your question via the Internet to help@sti.nasa.gov

- Fax your question to the NASA Access Help Desk at 301-621-0134

- Telephone the NASA Access Help Desk at 301-621-0390

- Write to:

NASA Access Help Desk

NASA Center for AeroSpace Information 7121 Standard Drive

Hanover, MD 21076 
NASA/CR-2004-213364

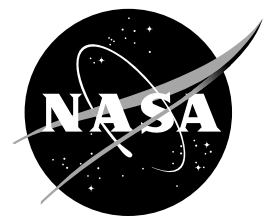

\section{Application of the GRC Stirling Convertor System Dynamic Model}

Timothy F. Regan and Edward J. Lewandowski

Sest, Inc., Middleburg Heights, Ohio

Prepared for the

Second International Energy Conversion Engineering Conference

sponsored by the American Institute of Aeronautics and Astronautics

Providence, Rhode Island, August 16-19, 2004

Prepared under Contract NAS3-03064

National Aeronautics and

Space Administration

Glenn Research Center 


\section{Acknowledgments}

This work was performed for NASA Headquarters, Office of Space Science (Code S) under the Project Prometheus Program and was supported by the NASA Glenn Research Center Contract NAS3-03064.

Available from

NASA Center for Aerospace Information 7121 Standard Drive

Hanover, MD 21076
National Technical Information Service 5285 Port Royal Road Springfield, VA 22100

Available electronically at http:/ /gltrs.grc.nasa.gov 


\title{
Application of the GRC Stirling Convertor System Dynamic Model
}

\author{
Timothy F. Regan and Edward J. Lewandowski \\ Sest, Inc. \\ Middleburg Heights, Ohio 44130
}

\begin{abstract}
The GRC Stirling Convertor System Dynamic Model (SDM) has been developed to simulate dynamic performance of power systems incorporating free-piston Stirling convertors. This paper discusses its use in evaluating system dynamics and other systems concerns. Detailed examples are provided showing the use of the model in evaluation of offnominal operating conditions. The many degrees of freedom in both the mechanical and electrical domains inherent in the Stirling convertor and the nonlinear dynamics make simulation an attractive analysis tool in conjunction with classical analysis. Application of SDM in studying the relationship of the size of the resonant circuit quality factor (commonly referred to as $\mathbf{Q}$ ) in the various resonant mechanical and electrical sub-systems is discussed.
\end{abstract}

\section{Nomenclature}

AreaD Area of displacer

$m_{p}, m_{d} \quad$ moving mass of convertor piston (p) or displacer (d)

$Q_{p}, Q_{d} \quad$ quality factor of piston's (p) or displacer's (d) resonant circuit

$S \quad$ pole location in the complex plane

$S d P \quad$ sum of pressure drops across heater, regenerator and cooler

$X_{p}, X_{d} \quad$ amplitude of piston (p) or displacer (d)

$\omega_{0} \quad$ operating frequency

\section{Introduction}

The free-piston Stirling convertor is being developed as an efficient and reliable power source for NASA exploration missions. The 110 watt Stirling Radioisotope Generator (SRG110) project is being conducted by the U.S. Department of Energy with system integrator Lockheed Martin, Valley Forge, Pennsylvania. The project will integrate two Stirling convertor assemblies (SCA's) into a space power generation system. ${ }^{1}$ The SCA's used are the 55 We Technology Demonstration Convertor (TDC) ${ }^{2}$ manufactured by Stirling Technology Company (STC), Kennewick, Washington. Predictions about how the SRG110 will behave under mission conditions can be made by test and simulation. The simulation tool under development at NASA's Glenn Research Center (GRC) is the Stirling Convertor System Dynamic Model (SDM). It can be used to predict SRG110 dynamic performance under mission conditions of interest. The simulation results can be reviewed and decisions can be made about follow-on studies or hardware tests based on the simulations. The model has been configured to take thermal power as input and give electrical power, temperatures and mechanical motion as outputs. In this paper, use of the model is demonstrated by presenting simulation results and comparing them to test data. Development of the model is treated in Ref. 3 through 5. Another application of the model is as an aid in controller design. This subject was treated in Ref. 6 and 7 and is not discussed further here. The final application that is discussed is the use of simulation as an alternative to classical analysis techniques in understanding the behavior of a convertor systems comprised of more than one SCA. Berchowitz has presented full details concerning the dynamics of a single SCA using classical analysis. ${ }^{8}$ Simulation can be a more practical analysis technique than classical analysis to answer questions about electronic controllers and multiple SCA interactions. 


\section{Application: Prediction of Off-nominal Behavior}

A number of simulations have been performed to date as part of the SDM validation effort. Reviewing these simulations gives some insight into the model's application as a means to investigate system behavior under offnominal conditions. This is a step in evaluating the system reliability. In the reliability evaluation, component values and operating conditions are made to vary within a band of values. As they vary, it is to be expected that at some point, operation will be affected. For example, if the cold-end temperature were increased by a certain percentage, one would expect the convertor performance to be reduced. A computer code like Sage ${ }^{9}$ can be used to evaluate losses and output power at the off-nominal cold-end temperature -- it was written to evaluate Stirling machine performance. The SDM is able to simulate system dynamics under the same off-nominal conditions. What can look like reduced but acceptable performance under a Sage ${ }^{9}$ analysis can conceivably register as a failure in a reliability study when dynamic performance analyzed by SDM is considered. The reason is that the imbalances which cause system instability can be detected by SDM. By analyzing unbalanced operation cases with both Sage ${ }^{9}$ and SDM, the boundaries between acceptable performance and unacceptable performance can be mapped not only for cold-end temperature variation but for any parameter or combination of parameters desired. Table 1 shows some descriptions of simulations that have been run.

Table 1.-Simulations performed as part of SDM validation.

\begin{tabular}{|c|l|c|}
\hline Simulation & \multicolumn{1}{|c|}{ Simulation Description } & System \\
\hline A & Single simulation, changing values of SCA-1 Tuning capacitance. & Single SCA \\
\hline B & Multisimulation, SCA-1 Tuning capacitance as parameter. & Dual-opposed \\
\hline C & Multisimulation, SCA-1 and -2 Tuning capacitance as parameter. & Dual-opposed \\
\hline D & Multisimulation, SCA-1 cold end temperature as a parameter. & Dual-opposed \\
\hline
\end{tabular}

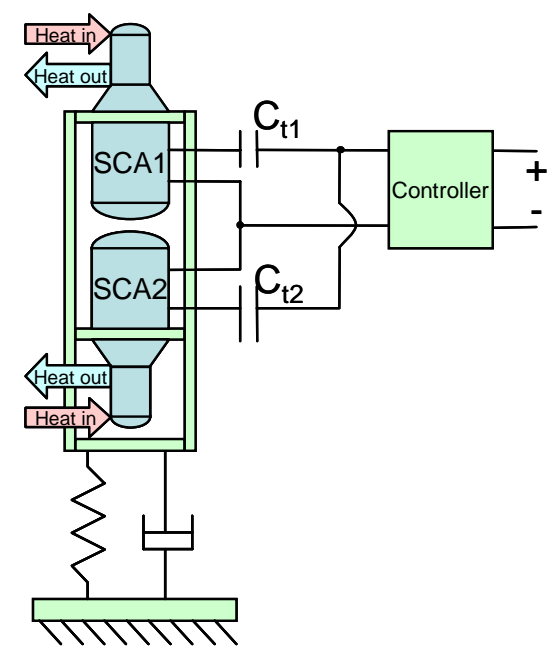

Figure 1a.-Dual opposed Stirling convertors flexibly mounted to a rigid base.

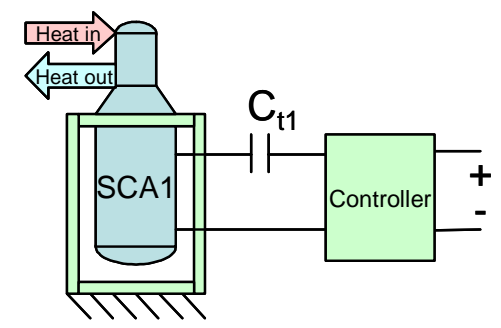

Figure 1b.-Single convertor rigidly mounted to a base.

The single system listed in Table 1 includes one SCA with its case mounted to ground. The single system is shown in Figure 1b. Simulations listed in Table 1 as dual systems include two SCA's in the general configuration shown in Figure 1a. The mounting mass, stiffness, and damping shown in Figure 1a were chosen to match the mounting conditions measured on the test stands of the GRC Stirling Research Lab. In the space power system evaluation, the mounting must reflect the vehicle's mounting conditions. In validation, the exact test conditions are modeled because the results will be compared to test results. 


\section{A. Simulation of tuning capacitor changes}

Simulation A is a single SCA simulation using off-nominal values of tuning capacitance. The tuning capacitor is a system component used to correct the power factor of the alternator so that the alternator current can be minimized. There are mass reduction benefits associated with minimizing alternator current. The tuning capacitor forms a resonant circuit with the alternator stator inductance. The tuning capacitance required to meet the minimum stator current design objective also makes the resonance frequency of the electric circuit the same as the operating frequency of the convertor. The value of the tuning capacitor therefore can have an effect on system dynamics.

In the simulation, a fixed input power was applied to the hot end. The hot-end temperature was allowed to float.
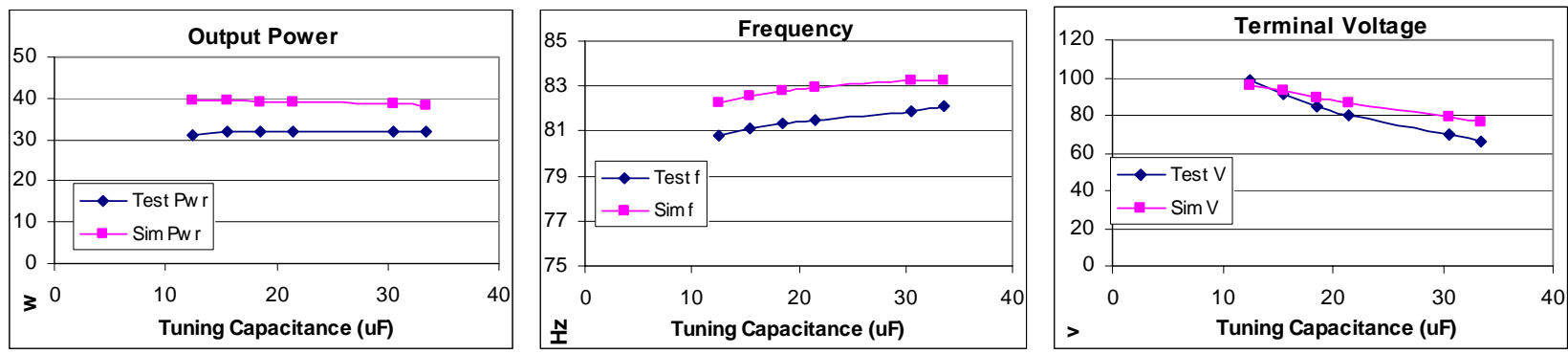

Figure 2.-Comparison of test result with simulation result -- output power (left) operating frequency (center) and terminal voltage (right) Configuration of Figure 1b was used with off-nominal tuning capacitors. Tuning capacitance shown as abscissa.

The cold-end temperature was fixed. The capacitance value was increased above and below the design value to match the test cases that were run. The simulated power, frequency and terminal voltage tracked the values measured in test in general. In testing, tuning capacitance was increased to a factor of 2.16 times nominal. Over this range, no instability was observed. The graphs of Figure 2 track the performance of both the test and the simulation in relation to the value of tuning capacitance connected. The alternator terminal voltage and operating frequency were predicted well by the model. The output power calculated by SDM is high because of the isothermal assumption used to model the thermodynamic cycle. SDM does not calculate all the known losses because the development plan calls for SDM to run Sage in background to improve the thermodynamic modeling of the cycle. Sage is a program that calculates Stirling machine performance including losses. When the Sage interface upgrade is accomplished, the output power simulated will be more accurate. The simulated displacer phase angle although not shown in Figure 2 was also low (by about $11^{\circ}$.) The phase angle discrepancy is also an artifact of the isothermal assumption and will be also corrected with the Sage interface.

Values of tuning capacitance larger than what is shown in Figure 2 were also used in the single SCA simulation in order to predict the value at which instability will occur. A tuning capacitance value of $50 \mu \mathrm{F}$ caused instability in the simulation. In that case, the cause of instability was that the load limit of the controller had been reached. It is the controller that determines the alternator current that in turn provides the electromagnetic damping force which extracts real power from the piston. The controller accomplishes this by reducing or increasing load resistance seen by the alternator until the circuit voltage satisfies a set point. With the proper value of tuning capacitance connected, the stator current required to extract rated power from the piston is well within the capability of the controller. In the case of an off-nominal value of tuning capacitance the power factor is lower and more current is required. With a $50 \mu \mathrm{F}$ tuning capacitor, the controller could not synthesize the electrical resistance required for the necessary current. The controller can synthesize any load required by normal operation of the convertor plus a margin. At some point in off-nominal operation, the margins will be exceeded and in the case of the single SCA simulation, the margin was exceeded at $50 \mu \mathrm{F}$ of tuning capacitance. The value has not been tested in hardware and in fact it is likely to experience instability with a tuning capacitor lower than $50 \mu \mathrm{F}$.

As has been pointed out, one cause of instability of a single SCA when operated with off-nominal tuning capacitors is the limit of load available from the controller. Another is a limitation of flux flowing in the alternator core. The alternator is modeled in the SDM with infinite flux-producing capability and so the present version of the SDM does not model the instability caused by flux limitation. The importance of mass reduction in aerospace applications implies that alternator cores, which are made of iron, must be sized to carry design flux plus margin and no more. For that reason, it is important for the SDM to incorporate flux limits in its alternator model. 
The modeling platform used by SDM has a magnetics physical domain available. The magnetics physical domain contains all the circuit elements necessary to model the flux limitation of the core used in an SCA. This suggests another upgrade to the SDM: incorporation of a non-linear alternator flux versus excitation characteristic.

\section{B. Simulation of unbalanced tuning capacitance}

Simulation B is a simulation of a dual-opposed system at about half rated power in which the value of one of the tuning capacitors was changed while the other remained fixed. The tuning capacitance for SCA-1 was changed. That of SCA-2 remained unchanged. The heat input was fixed and the hot-end temperatures of each SCA was allowed to
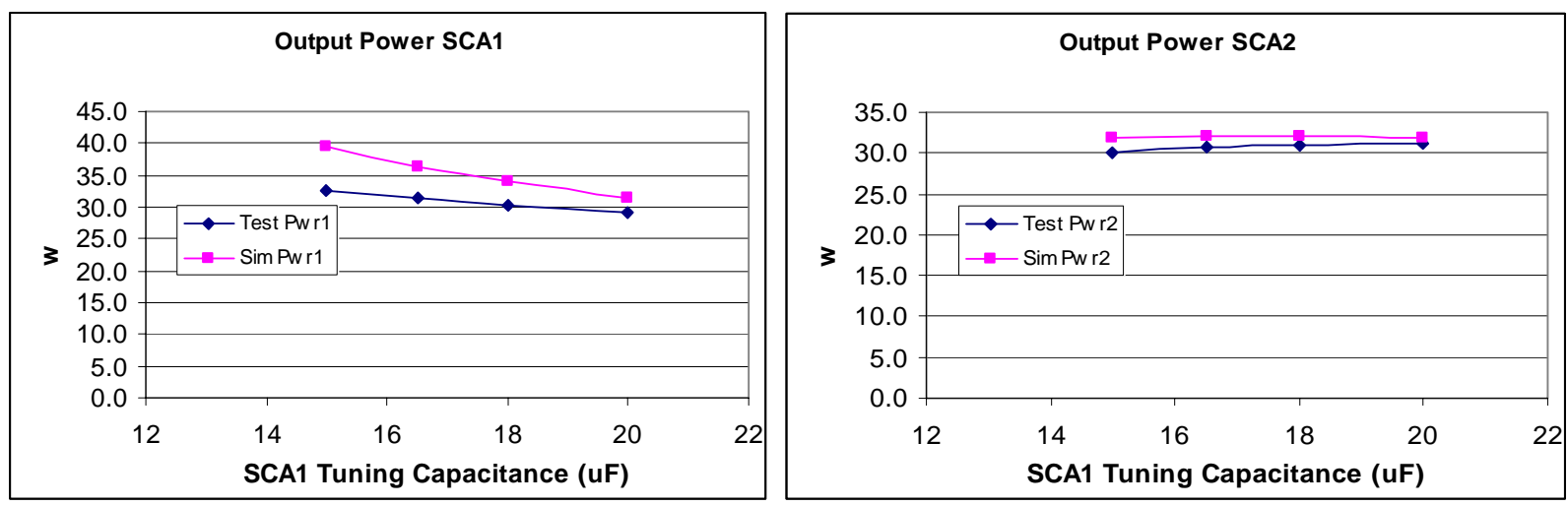

Figure 3.-Comparison of test with simulation results for SCA-1 and SCA-2 output power in dual-opposed simulation (Fig. 1b) with unbalanced tuning capacitors.
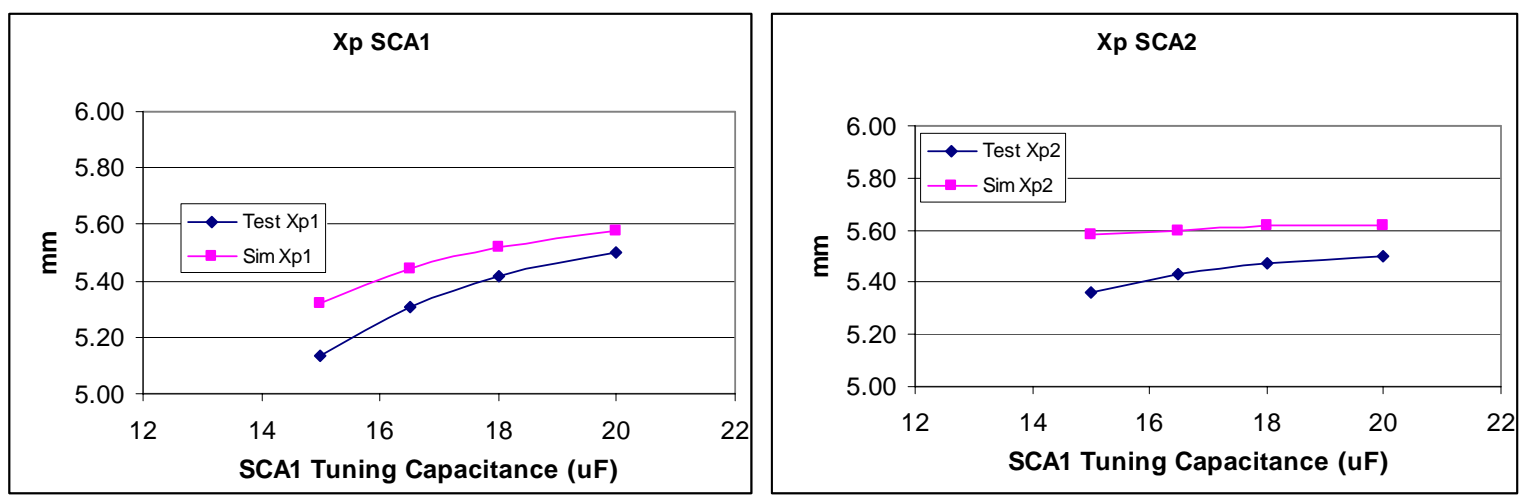

Figure 4.-Comparison of test with simulation results for SCA-1 and SCA-2 piston amplitude in dualopposed simulation (Fig. 1b) with unbalanced tuning capacitors.

float. In this simulation, the unbalance was observed to cause motion of the case mass. The motion of the case mass in turn causes additional effects in performance. Simulation B was performed at power levels that were well below rated power. The flux limitation discussed under simulation $\mathrm{A}$ is related to the alternator current level. In simulation $\mathrm{B}$, the alternator current level never exceeded the rated alternator current, due to the reduced power level at which the simulation was conducted. As a result, the flux limit of the hardware was not exceeded in the simulation. The simulation results are compared with the test results in Figures 3 and 4. Again, due to the isothermal assumption of $\mathrm{SDM}$, the output powers in the simulation were greater than those of the test results but the trend with increasing tuning capacitance was in agreement with test results. The model predicts the dynamic performance as represented in Figure 3 by piston amplitudes. The frequency of operation, not shown tracked the test results $1 \mathrm{~Hz}$ higher at each of the 4 test points. 


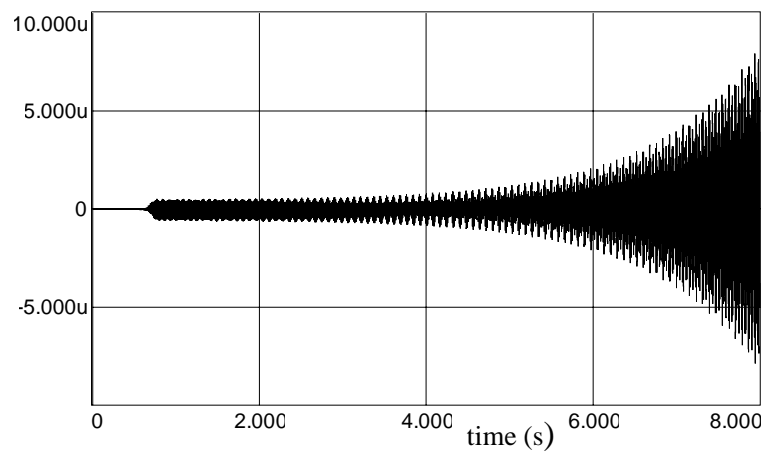

Figure 5.- Instability as a result of balanced tuning capacitors whose value exceeded the nominal value by factor greater than the margin in simulation $\mathrm{C}$.

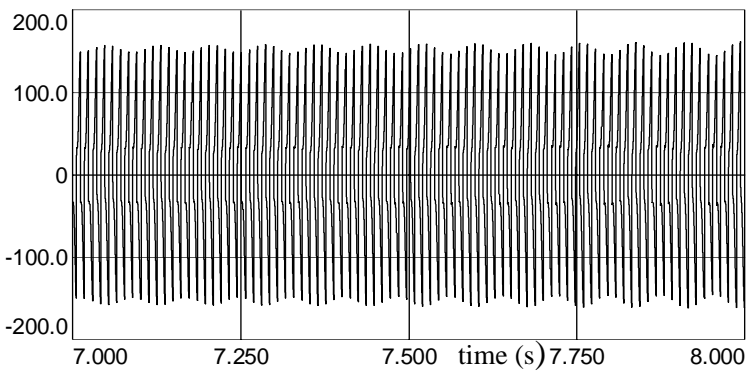

Figure 6.-Terminal voltage of SCA1 in a dual simulation according to Figure 1a with $20 \mathrm{uF}$ tuning capacitors and $40 \mathrm{w}$ output. $13 \mathrm{~Hz}$ subsynchronous oscillations shown.

\section{Simulation of balanced but off-nominal tuning capacitance}

Simulation C was performed to further investigate tuning capacitance variation. The dual-opposed arrangement of Figure 1a was again used. The tuning capacitors that are connected to each SCA were kept equal to each other but a value of capacitance 1.23 times the design value was used. This was a value that was known to cause instability in test. The test demonstrated unstable operation of the system when output power was 40 We. The simulation used the constant input power level required to convert $40 \mathrm{We}$ per SCA. The simulation predicted instability as shown by the exponential rise in case motion shown in Figure 5 .

Another prediction of the SDM was the form and frequency of the sub-synchronous oscillations observed in the testing. In test, the onset of instability was accompanied by a $9 \mathrm{~Hz}$ sub-synchronous beat frequency. One second's worth of the alternator terminal voltage is shown in Figure 6. In simulation, a beat frequency of $13 \mathrm{~Hz}$ was predicted as shown in Figure 6.

\section{Simulation of Unbalanced Cold-End Temperature}

Simulation D simulated the effects of an unbalanced cold-end temperature on operation. The test and simulation are of practical interest because the cold end temperatures of an SRG110 may vary if one SCA is exposed to more sunlight than the other SCA. In such a case, the cold-end temperature and the bounce-space temperature may be presumed to be different. Three cases were considered in test and simulation. Simulation D considered balanced temperatures at the extremes and an unbalanced temperature in the center. In the unbalanced case, both the cold-end temperature and the bounce-space temperature are different. The test results are compared to simulation results in Figure 7.
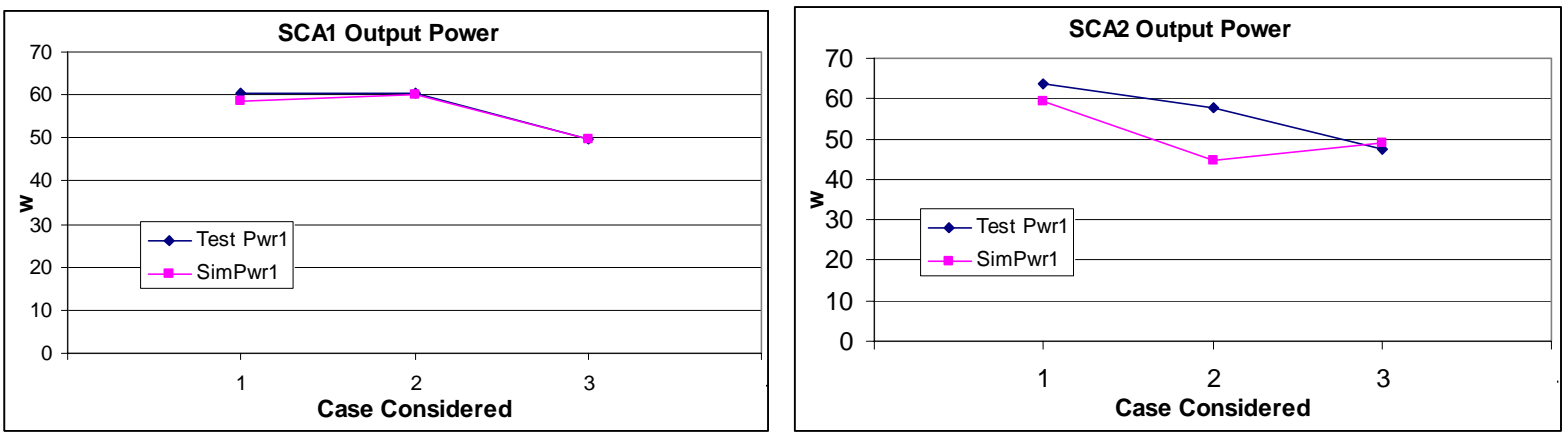

Figure 7.-Comparison of test and simulation output power for dual SCA configuration according to

Figure 1a with constant heat input and shade-to-sun temperature transition.

Case 1 - full shade, Case 2 - transition, Case 3 - full sun. 
SCA1 results show excellent agreement between test and simulation. The output power of SCA2 behaves differently in simulation than in test in the middle temperature case. The transition case is the case for which the SDM calculated most unbalance in the dynamics.

\section{Application: SDM as an Aid to Analysis of Convertor Systems}

In Ref. 8, Berchowitz has described an elegant treatment of the linear dynamics of free-piston machines. It used complex analysis to derive expressions for complete dynamics including starting conditions and operating frequency of a single convertor. The analysis used the calculated Q (or quality factor) of the piston and displacer resonant circuits to derive the pole locations in the complex plane as the operating point of the machine is varied. The linear analysis derives $\mathrm{Q}$ from linearized equations of piston and displacer motion. SDM can compute the value of Q from measurements of piston and displacer motion. The $\mathrm{Q}$ of a resonant circuit is the ratio of stored energy to dissipated energy per cycle. The mass, spring, and damper of the piston in a free-piston machine is such a circuit. Its kinetic energy can be calculated as a function of its frequency and amplitude as in Eq. (1), assuming sinusoidal motion.

$$
K E=\frac{1}{2} \cdot m_{P} \cdot \omega_{o}^{2} X_{P}^{2}
$$

The energy converted to electrical power is the energy dissipated per second, Pe. The energy dissipated per cycle is $P_{e} / f_{o}$ where $f_{o}$ is the operating frequency in $\mathrm{Hz}$. Then the piston Q is calculated as the ratio of stored energy to dissipated energy per cycle.

$$
Q_{P}=\frac{m_{P} \cdot \omega_{o}^{2} X_{P}{ }^{2}}{2 P_{e} / f_{o}}
$$

The value of $Q_{P}$ is seen to change as the piston amplitude and output power change. SDM has been configured to calculate the value of $Q_{P}$ with time. Typical results are shown in Figure 4.

A similar definition holds for the displacer mechanical circuit. The power dissipated in the displacer circuit is calculated by SDM as

$$
P_{D}=S d P \cdot \operatorname{AreaD} \cdot \omega_{o} X_{D} / \sqrt{2}
$$

where $S d P$ is the sum of the pressure drops across the heat exchangers and regenerator and $X_{D}$ is the displacer amplitude. The displacer $\mathrm{Q}$ is then

$$
Q_{D}=\frac{m_{D} \cdot \omega_{o}^{2} X_{D}^{2}}{2 P_{D} / f_{o}}
$$

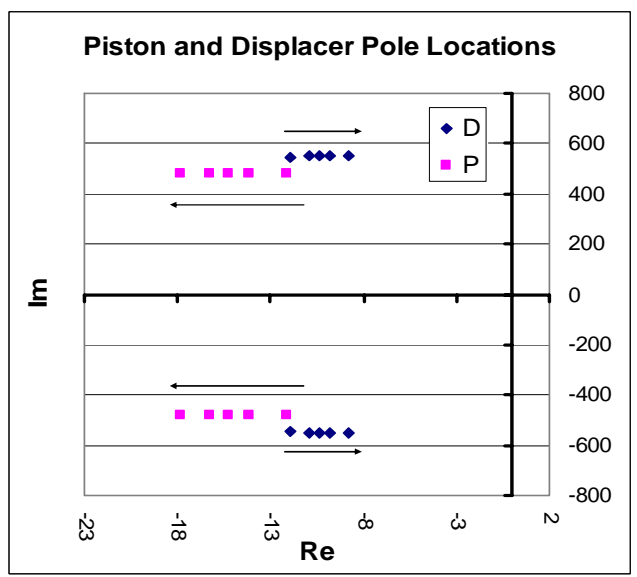

Figure 8.-Location of the piston and displacer poles for several operating points as calculated by SDM. Arrows show the location as output power increases. 
the piston and displacer Q values were calculated by SDM and used to determine pole locations in the complex plane. The calculation is from Eqs. 5 and 6 obtained directly from Ref. 8. The results are plotted in Figure 8.

$$
\begin{aligned}
& s_{d 1}, s_{d 2}=\omega_{d} \cdot\left[-1 /\left(4 \cdot \pi \cdot Q_{d}\right) \pm j \sqrt{1-\frac{1}{4 \cdot \pi \cdot Q_{d}}}\right] \\
& s_{p 1}, s_{p 2}=\omega_{p} \cdot\left[-1 /\left(4 \cdot \pi \cdot Q_{p}\right) \pm j \sqrt{1-\frac{1}{4 \cdot \pi \cdot Q_{p}}}\right]
\end{aligned}
$$

The piston poles are represented by the progression of squares moving to the left in Figure 8. The poles move to the left as output power increases. The displacer poles of the convertor analyzed move to the right as power increases. As pointed out by Berchowitz, the operating frequency of the final operating point of the convertor can be determined graphically from the piston and displacer pole locations. ${ }^{8}$ Knowledge of the location of the piston and displacer poles in the complex plane can also be used to advantage in system identification.

In addition, modeling of a system with SDM makes all pressures, pressure drops, motions and temperatures available for display and further analysis. Phasor diagrams are very useful tools to be used in visualizing operation of a Stirling convertor system. The SDM makes magnitudes and angles of all periodic signals available to the analyst so that phasor diagrams can be constructed.

\section{Conclusion}

It has been shown that system behavior of interest in dynamics and reliability studies can be obtained from NASA GRC's Stirling Convertor System Dynamic Model (SDM). The dynamic effects of unbalanced operation can not be evaluated using other software tools available. Examples considered included unbalanced temperatures and unbalanced tuning capacitance. Since the SDM is physics-based, it is also convenient to study unbalances in component characteristics - the regenerator fiber diameter as an example.

Two important SDM improvement areas have been pointed out and the plan for incorporating them has been mentioned:

1.) Incorporation of more realistic modeling of the alternator core

2.) Incorporation of more sophisticated thermodynamic modeling of the cycle by running Sage in the background

Use of a simulation model of a nonlinear aids understanding of system behavior by making all the states available for inspection and analysis. In a practical space application, it is necessary to understand the limits of parameter variation that cause unacceptable operation as in the reliability evaluation discussed. It is also necessary to understand which component values can be adjusted to obtain more reliable dynamic performance.

\section{References}

${ }^{1}$ Cockfield, R.D. and Chan, T.S., "Stirling Radioisotope Generator for Mars Surface and Deep Space Missions," in Proceedings of 37th Intersociety Energy Conversion Engineering Conference (I.E.C.E.C 2002), Institute of Electrical and Electronics Engineers, Piscataway N.J., 2002.

${ }^{2}$ Qiu, S., Augenblick, J.E., White, M.A., Pererson, A.A., Redinger, D.L. and Peterson, S.L., Developing a FreePiston Stirling Convertor for Advanced Radioisotope Space Power Systems," in Proceedings of the Space Technology and Applications International Forum, (STAIF 2002), American Physical Society.

${ }^{3}$ Regan, T.F., Gerber, S.S. and Roth, M.E. "Development of a Dynamic, End-to-End Free Piston Stirling Convertor Model," in Proceedings of 37th Intersociety Energy Conversion Engineering Conference (I.E.C.E.C 2002), Institute of Electrical and Electronics Engineers, Piscataway N.J., 2002.

${ }^{4}$ Regan, T.F., Gerber, S.S. and Roth, M.E. "Development of a Dynamic, End-to-End Free Piston Stirling Convertor Model” NASA/TM-2004-212941.

${ }^{5}$ Lewandowski, E.J. and Regan, T.F., “Overview of the GRC Stirling Convertor System Dynamic Model,” in Proceedings of the Second International Energy Conversion Conference (I.E.C.E.C 2004) (to be published) American Institute for Aeronautics and Astronautics, 2004. 
${ }^{6}$ Gerber, S.S., Jamison, M., Regan, T.F. and Roth, M.E., "Advanced Controller for the Free-Piston Stirling Convertor," in Proceedings of the Second International Energy Conversion Conference (I.E.C.E.C 2004) (to be published) American Institute for Aeronautics and Astronautics, 2004.

${ }^{7}$ Regan, T.F., "Free-Piston Stirling Convertor Controller Development at NASA Glenn Research Center," in Proceedings of the First International Energy Conversion Conference (I.E.C.E.C 2003) American Institute for Aeronautics and Astronautics, 2004.

${ }^{8}$ Berchowitz, D.M., Chapter 5, "Linear Dynamics of Free-Piston Engines," Stirling Cycle Engine Design and Optimization, Ph.D. Dissertation, Faculty of Engineering, University of the Witwatersrand, Johannesburg, U.S. Africa, 1986.

${ }^{9}$ Gedeon Associates, Sage User's Guide, $3^{\text {rd }}$ Ed., Gedeon Associates, Athens, Ohio, 1999. 


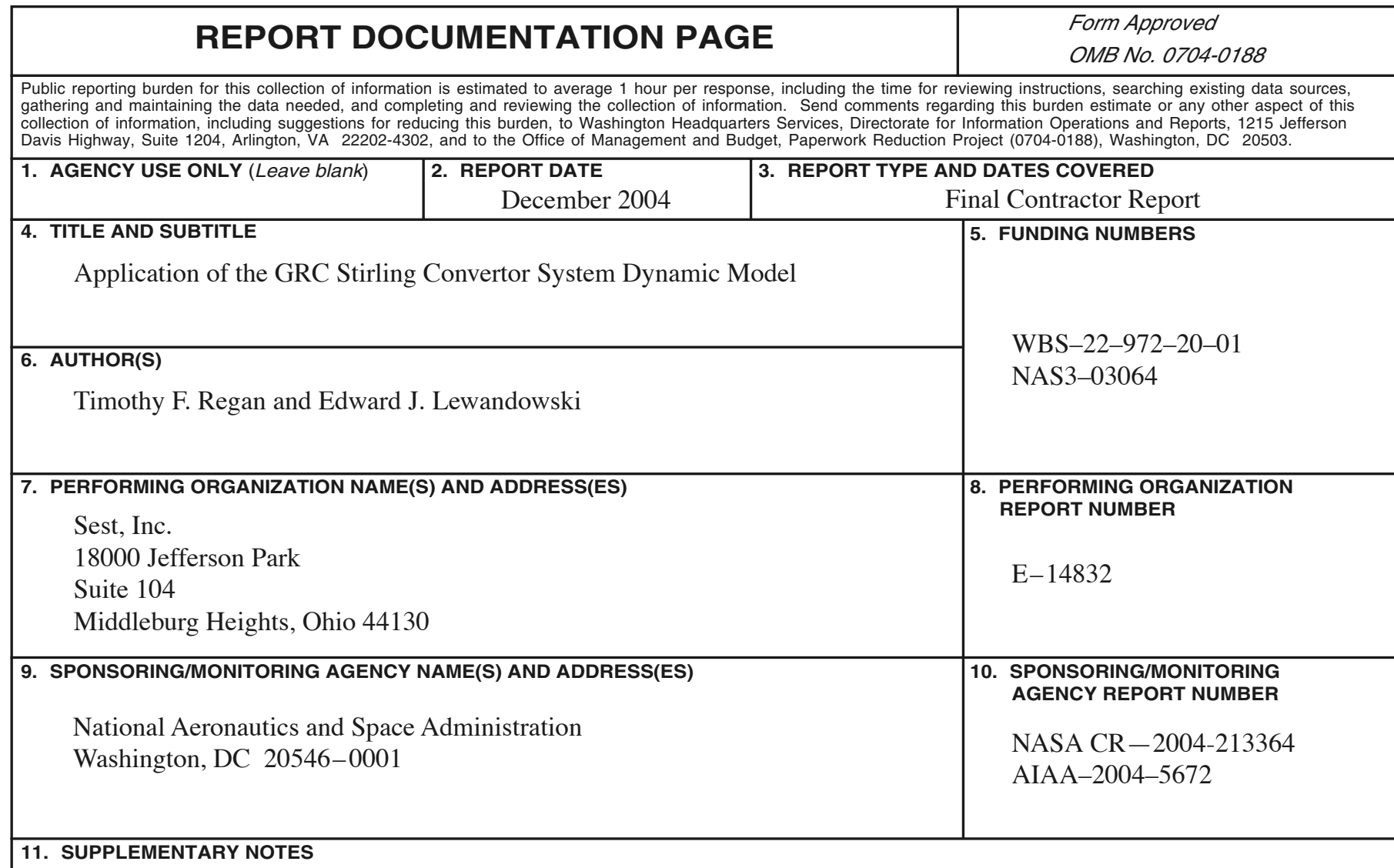

Prepared for the Second International Energy Conversion Engineering Conference sponsored by the American Institute of Aeronautics and Astronautics, Providence, Rhode Island, August 16-19, 2004. Project Manager, Jeffrey G. Schreiber, Power and On-Board Propulsion Technology Division, NASA Glenn Research Center, organization code 5490, 216-433-6144.

12a. DISTRIBUTION/AVAILABILITY STATEMENT 12b. DISTRIBUTION CODE

Unclassified - Unlimited

Subject Category: 20

Distribution: Nonstandard

Available electronically at http://gltrs.grc.nasa.gov

This publication is available from the NASA Center for AeroSpace Information, 301-621-0390.

13. ABSTRACT (Maximum 200 words)

The GRC Stirling Convertor System Dynamic Model (SDM) has been developed to simulate dynamic performance of power systems incorporating free-piston Stirling convertors. This paper discusses its use in evaluating system dynamics and other systems concerns. Detailed examples are provided showing the use of the model in evaluation of off-nominal operating conditions. The many degrees of freedom in both the mechanical and electrical domains inherent in the Stirling convertor and the nonlinear dynamics make simulation an attractive analysis tool in conjunction with classical analysis. Application of SDM in studying the relationship of the size of the resonant circuit quality factor (commonly referred to as Q) in the various resonant mechanical and electrical sub-systems is discussed.

\section{SUBJECT TERMS} 15. NUMBER OF PAGES

Stirling engines; Design analysis; Block diagrams; Electromechanics; Dynamic models; Simulation; AC generators; Linear alternators; Stirling cycle; Stability

\begin{tabular}{|c|c|c|c|}
\hline $\begin{array}{c}\text { 17. SECURITY CLASSIFICATION } \\
\text { OF REPORT } \\
\text { Unclassified }\end{array}$ & $\begin{array}{c}\text { 18. SECURITY CLASSIFICATION } \\
\text { OF THIS PAGE } \\
\text { Unclassified }\end{array}$ & $\begin{array}{c}\text { 19. SECURITY CLASSIFICATION } \\
\text { OF ABSTRACT } \\
\text { Unclassified }\end{array}$ \\
\hline
\end{tabular}



